\title{
RECORRÊNCIAS E CONVERGÊNCIAS DO IMAGINÁRIO: O DILÚVIO MÍTICO COMO MATRIZ IMAGINAL DE IDENTIDADE LOCAL APÓS UMA ENCHENTE
}

HELOISA JUNCKLAUS PREIS MORAES PONTIFÍCIA UNIVERSIDADE CATÓLICA DO RIO GRANDE DO SUL PORTO ALEGRE, RIO GRANDE DO SUL, BRASIL HELOISAPREIS@HOTMAIL.COM

WILLIAN CORRÊA MÁXIMO UNIVERSIDADE DO SUL DE SANTA CATARINA TUBARÃO, SANTA CATARINA, BRASIL WILLIAN.MAXIMO@UNISUL.BR

HTTP://DX.DOI.ORG/10.5902/2316882X22933 
RECORRÊNCIAS E CONVERGÊNCIAS DO IMAGINÁRIO: O DILÚVIO MÍTICO COMO MATRIZ IMAGINAL DE IDENTIDADE LOCAL APÓS UMA

\section{ENCHENTE}

Resumo: $O$ presente artigo apresenta, sob o enfoque do imaginário, uma análise da narrativa de moradores de Tubarão, Santa Catarina, sobre a presença do mito, especialmente do dilúvio, em relação à grande enchente de 1974. Tal fato configura-se, pelos relatos, em marcas de uma "cultura da enchente", que cria traços de identidade local e marcas de pertencimento. Como mostraremos, a comunidade se reconhece por uma narrativa mítica, épica e inacabada.

Palavras-chave: Imaginário; mito; enchente; dilúvio; pertencimento.

\section{LAS RECURRENCIAS Y CONVERGENCIAS DEL IMAGINARIO: LA INUNDACIÓN MÍTICA COMO MATRIZ IMAGINAL DE LA IDENTIDAD LOCAL DESPUÉS DE UNA INUNDACIÓN}

Resumen: En este artículo se presenta bajo el foco imaginario, un análisis de las narrativas de los residentes de Tubarão, Santa Catarina, en la presencia del mito , especialmente la inundación , en relación con la gran inundación de 1974. Este hecho se configura, por los informes, en las marcas de una "cultura de la inundación", que crea huellas de identidad local y marcas que pertenecen. Como se verá, la comunidad es reconocida por una narración mítica, épica y inconclusa.

Palabras-clave: Imaginario ; mito ; inundación; pertenencia.

RECURRENCES AND IMAGINARY CONVERGENCES: THE FLOOD MYTHICAL AS IMAGINAL ARRAY OF LOCAL IDENTITY AFTER A FLOOD

Abstract: This article presents under the imaginary focus, an analysis of the narrative Tubarão's residents, Santa Catarina, on the presence of the myth , especially the flood, in relation to the great flood of 1974. This fact is configured, by reports, in marks of a "culture of the flood", which creates traces of local identity and belonging brands. As we will show, the community is recognized by a mythical narrative, epic and unfinished.

Key-words: Imaginary; myth; flood; belonging. 


\section{O fato natural}

Março de 1974. Tubarão, sul de Santa Catarina. O vento leste e as chuvas que caiam na nascente no Rio à beira da Serra Geral fizeram com que o rio, homônimo da cidade, subisse 10 metros e deixasse como registro a maior catástrofe natural do estado. "A enchente de Tubarão deixou 60 mil desabrigados e 3 mil casas destruídas. Por três dias, $90 \%$ da cidade ficou submersa"'. Hoje, conforme censo IBGE (2010), com aproximadamente 100 mil habitantes, é uma dessas comunidades que possui um elo imaginal, de forma significativa, sustentado e consolidado pelas narrativas cotidianas de seus moradores em relação à catástrofe. Fato ocorrido há mais de 40 anos, ainda hoje se presentifica nos atos, relatos e ritos locais. É é por isso que este fato natural, tão socioculturalmente arraigado nesta comunidade, nos interessa.

\section{Pelas vias do imaginário}

As relações sociais, suas manifestações, artefatos e processos, são causa e efeito de dimensões imaginárias. Para além de uma mera representação imagética, o imaginário é uma atmosfera, arquetipal, atemporal e coletiva, que nutre o universo simbólico e mental dos indivíduos, estabelecendo vínculos.

As nações, os estados, as cidades e mesmo as comunidades são imaginadas, projetam imagens de comunhão, mas, sobretudo, evidenciam o lastro do imaginário em seus cotidianos, "sedimentando" identidades, identificações, laços de pertencimento, confiança e cultura, mesmo no anonimato e nas particularidades culturais de seus indivíduos.

Esta cumplicidade das comunidades imaginadas (e imaginais) se consolidam pela linguagem, por intermédio de trajetos antropológicos, que perpassam o tempo, em espaços discursivos repletos de narrativas que historicizam cada processo de significação.

Dilúvio é termo que evoca e converge um léxico de imagens e significados. Do grego Deucalião ao mito sumério de Gilgamesh, passando por Noé e os relatos cataclísmicos dos ameríndios, tal narrativa mítica perpassa gera-

1 Especial "40 anos da Enchente" publicado em 2014 no Diário Catarinense. Disponível em http://dc.clicrbs.com.br/sc/noticias/noticia/2014/03/tragedia-de-1974-em-tubarao-sc-nao-tem-lista-oficial-de-mortos-ate-hoje-4453041.html

Rev.Cad.Comun. Santa Maria, v.20, n.3, art 9, p.182 de 191, set/dez.2016 
ções e, ao se (res)significar, viabiliza uma matriz imaginal: um pecado; uma comunidade; um Deus punitivo; um herói; uma aliança; e os testemunhos. Basta um relâmpago, precipitação e o sopro do 'lestada' para partilhar de uma atmosfera (re)inventada. A seguir, a partir do mito da Grande Enchente de 1974, por intermédio do teste arquetípico dos nove elementos, propõe-se identificar - na transversalidade das narrativas dos tubaronenses - elementos que presentificam o dilúvio, cujos sinais evidenciam um imaginário e uma comunidade imaginada que se reconhece por uma narrativa mítica, épica e inacabada.

De acordo com G. Durand (2002) todo imaginário humano articula-se por meio de estruturas plurais e irredutíveis, limitadas a três classes que gravitam ao redor dos processos matriciais do 'separar' (heroico), 'incluir' (místico) e 'dramatizar' (disseminador), ou pela distribuição das imagens de uma narrativa ao longo do tempo.

Assim, o imaginário constitui o conector obrigatório pelo qual forma-se qualquer representação humana. Há uma concomitância entre os gestos do corpo, os centros nervosos e as representações simbólicas. G. Durand (2002) fala dos reflexos: o da posição (ereta para o homem) corresponde à imagem de elevação, divisão, luta; reflexo da deglutição, imagens de interiorização, descida, harmonização; reflexo de copulação: imagens de ciclicidade, de ritmo, de diálogo, de progresso.

Durand (2002) divide o universo em opostos; e unindo os opostos, complementando, harmonizando. $O$ primeiro corresponde ao regime diurno de imagens; o segundo, ao noturno, como a noite, que concilia e unifica. Os dois regimes da imagem recobrem três estruturas do imaginário, que dão resposta à questão fundamental do homem: sua mortalidade.

Os símbolos expressam a angústia e se dividem em três grandes temas. Os símbolos teriomórficos, relativos à animalidade (animal simbólico) onde encontramos o fervilhamento: repugnância primitiva diante da agitação incontrolável - arquétipo do caos; a animação: o movimento em si, incontrolável, dos grandes animais; a mordicância ou ato de morder, de devorar, outro aspecto angustiante. Os símbolos nictomórficos, relativos à noite, à escuridão, trazem situações das trevas (como a água escura). Já os símbolos catamórficos, relativos à queda, medo, dor, vertigem, castigo.

Através das imagens que povoam nossa imaginação e imaginário, aqui pespecialmente a partir do elemento água, buscamos rastros do modelo primitivo. Entre o dilúvio mítico, nas diferentes culturas, e a enchente que nos

Rev.Cad.Comun. Santa Maria, v.20, n.3, art 9, p.183 de 191, set/dez.2016 
propomos a estudar, há imagens arquetípicas, recorrentes e convergentes. Estamos chamando de recorrência simbólica, "o processo pelo qual determinado mitema ${ }^{2}$ atravessa a narrativa (textual ou imagética), de modo a reiterar seu nível de pertença a um registro simbólico específico ou estrutura de sensibilidade" (SANTOS e ALMEIDA, 2012, p. 76). E, de maneira muito recorrente, a enchente aparece como símbolo de pertencimento na narrativa e nas ações e práticas cotidianas dos tubaronenses que, inclusive, já se tornaram marcas desta comunidade. O mitema enchente é marca de identidade desta comunidade local imaginada, em que os vínculos de pertencimento ancoram-se nas memórias vividas ou herdadas. A nossa investigação busca, sob o viés do imaginário, identificar estas marcas míticas e arquetipais.

A enchente aparece, na nossa visão, não apenas como traço simbólico do imaginário local, mas também como marca de uma ancestralidade, aqui, através do mito do dilúvio. Durand (2002, p.62) define o mito como "um sistema dinâmico de símbolos, arquétipos e esquemas, sistema dinâmico que, sob impulso de um esquema, tende a compor-se em narrativa. O mito é já um esboço de racionalização, dado que utiliza o fio do discurso, no qual símbolos se resolvem em palavras e os arquétipos em ideias".

A água, para além de uma substância química cujas moléculas são formadas por dois átomos de hidrogênio e um de oxigênio, é uma experiência onírica (dos sonhos e para além de), ambivalente. É um arquétipo, tem raiz ancestral. Nos dizem Santos e Almeida (2012, p. 60):

A ancestralidade é uma herança que pode ser biológica, todavia não necessariamente biológica, pois que pode ser herdade através dos ritos de iniciação. Neste caso, optamos por determinadas tradições culturais ou grupo de ancestrais, por aproximações sucessivas até que o rito de iniciação consuma a herança. Essa herança coletiva pertence ao grupo comunitário, a que por sua vez, eu pertenço e me ultrapassa.

Os autores (SANTOS e ALMEIDA, 2012, p. 60) afirmam que esta ancestralidade se presentifica através de duas estratégias, a saber: a memória e a provação. A memória diz respeito aos ritos que relembrem sobre a herança

$2 \quad$ Na obra de Durand, mitema é a menor unidade do discurso miticamente significativo, ou seja, está no campo das significações (e não sintática, como o termo em Levi-Strauss) (TURCHI, 2003, p. 40).

Rev.Cad.Comun. Santa Maria, v.20, n.3, art 9, p.184 de 191, set/dez.2016 
e o seu pertencimento (quem é e a qual cultura pertence). A provação são os testes de pertencimento: imaginário do pertencimento que é convidado a manifestar a sua "fidelidade, correção e apropriação". E esta ancestralidade, em suas marcas míticas e arquetipais, vão se atualizando, ressignificando, como na nossa situação de análise:

A ancestralidade se atualiza em nossas criações, principalmente nas "situações-limites" (die Grenzsituation, como quer Karl Jaspers), de risco da própria sobrevivência, propiciando a religação (re-ligare) e releitura (re-legere) da pessoa em relação à sua querência, ao seu rincão, seu lugar, sua própria paisagem. Nas situações limites é que o ser humano revela sua face. É nessa situação-limite que eu atualizo o mito de origem e pode ocorrer tanto a religação com essa minha ancestralidade, na sua estratégia de religare, quanto na sua outra possibilidade latina que é relegere - eu me religo às pessoas e passo a reler o mundo, passo a interpretá-lo de uma outra maneira quando exerço essa pertença. É quando, então, nos assumimos como herdeiros de fato, não de uma maneira inconsciente, mas com uma tomada de consciência da própria pessoa em relação à sua querência, sua origem ou sua opção cultural. (SANTOS e ALMEIDA, 2012, p. 63).

Interessante percebermos que a Enchente de 1974 ocorrida na cidade de Tubarão, Santa Catarina, é mitema recorrente e funciona como uma religação, tal como apontada acima pelos autores, e que garante o pertencimento a esta comunidade imaginada. Na cidade, comemora-se o aniversário da enchente, o que quer dizer, em última instância, a conquista frente à tragédia. Os tubaronenses se recriaram depois do ocorrido e esta angústia existencial vem acompanhada de símbolos de heroísmo. A finitude, os semblantes do tempo e a fúria da natureza foram percebidos, vivenciados e vencidos. Só que este embate deixou marcas que se presentificam nas narrativas diárias, como veremos no experimento realizado.

O insconsciente marítimo (e mais do que isso pela potência simbólica que dispõe, o imaginário hídrico, marítimo) é, portanto, um inconsciente falado, um inconsciente que se dispersa em narrativas de aventuras, um inconsciente que não dorme. Para Bachelard (1998), antes de ser um espetáculo consciente, toda paisagem é uma experiência onírica. A água, como um dos quatro elementos chave estudados pelo autor, guarda o início, a vida, a morte e a renovação em sua substância. Ela (a água) que coloca em oposição o sagrado (e a vida religiosa) e o profano (a vida secular); a água oculta

Rev.Cad.Comun. Santa Maria, v.20, n.3, art 9, p.185 de 191, set/dez.2016 
o céu, sendo metáfora do caos, da transformação, da resiliência.

A água mistura, em seus símbolos, reminiscências e devaneios divinatórios. Podemos traçar relação com o destino do ser humano que, assim como da água, corre, caracterizando-se como um elementos transitório. É, segundo Bachelard (1998), a metamorfose ontológica essencial entre o fogo e a terra. A morte cotidiana não é a morte exuberante do fogo que perfura o céu com suas flechas; a morte cotidiana é a morte da água. A água corre sempre, a água cai sempre, acaba sempre em sua morte horizontal.

Assim, a enchente de 1974 ocorrida em Tubarão, Santa Catarina, mais do que uma catástrofe natural, configura-se até hoje como uma narrativa épica, mítica, transmitida de geração para geração. Sua força simbólica está nas narrativas de sua população, sejam os nativos ou diaspóricos. Configura-se como mote de identidade local, símbolo de pertença. Além disso, simboliza o ressurgimento diante do quase-fim. Da catástrofe à vida.

A água, fonte de vida, assume um rancor, muda de sexo. De feminina, torna-se má, masculina, voraz. A água silenciosa, água sombria, água dormente, água insondável, quantas lições materiais para uma meditação da morte. Quantos atitudes imaginais para romper com os semblantes do tempo. Para vencer a finitude e, principalmente, para manter o fio discursivo que permite, mitologicamente, ter vencido o dilúvio, a fúria das águas de um rio.

Em Tubarão, basta um vento noturno para que a água que volte a rugir, bastará um raio para dialogarmos com o divino, bastará um raio de lua, muito suave, muito pálido, para que o fantasma caminhe de novo sobre as ondas, do mar e do rio. Segundo Eliade (1992), o mito conta uma história sagrada; ele relata um acontecimento ocorrido no tempo primordial, o tempo fabuloso do 'princípio'; o mito é considerado uma história sagrada e, portanto, uma 'história verdadeira', porque sempre se refere a realidades.

Eliade (1992, p.60) esclarece que o tempo do mito é o tempo total e o evento fundador pode ser ressuscitado a cada momento da vida. Aí estaria a essência do sagrado. Presente a hierofania, o episódio mítico fundador, o mito irriga a história, lhe dá sentido. O mito fundador configura-se como uma ponte. A imagem simbólica é ativada, dotada de um poder imediato de transformação daquele que a vê, e logo a vive. As imagens simbólicas são reagrupadas em relatos organizados, os mitos.

Rev.Cad.Comun. Santa Maria, v.20, n.3, art 9, p.186 de 191, set/dez.2016 


\section{Comunidade local e imaginada}

A partir da Teoria do Imaginário (DURAND, 2002), que legitima imagens e imaginação enquanto potência simbólica, e sob o método da sociologia compreensiva (MAFFESOLI, 2007), que contextualiza fenômenos sociais e o imaginário no cotidiano, este estudo instrumentaliza-se a partir do teste arquetipal dos nove elementos (AT-9), modelo experimental de Yves Durand. O teste aponta elementos de universos míticos (ELIADE, 1992), representados através de nove estímulos arquetípicos: personagem, queda, espada, refúgio, monstro, cíclico, água, anima e fogo.

Em Tubarão, a amostra contemplou representantes de nativos e diaspóricos: dois residentes, desde a enchente de 1974; e dois emigrantes, pós-74. A primeira etapa do AT-9 levou o respondente a representar, em até $30 \mathrm{~min}$., algum ou todos os elementos arquetípicos; a segunda, convidando-o a redigir sobre o desenho; a terceira, com aplicação de questionário sobre a ideia central, predileção e/ou eliminação de algum dos nove elementos, participação (caso estivesse em cena), atitude no contexto representado, além da conclusão da história; a quarta etapa previu o preenchimento de um quadro síntese com os nove elementos, formas de representação e funções simbólicas. Experienciou-se ainda a inclusão de uma quinta fase: entrevista, a partir de outras nove 'iscas semânticas': Tubarão; 1974; chuva; rio; rádio Tubá; vento leste (ou lestada); Irmoto; Catedral; e solidariedade; narrativas que convergem 'bacias semânticas' (SILVA, 2003) para uma comunidade imaginada (ANDERSON, 2006) - uma matriz - possibilitando sentimento de pertença e a partilha da angústia, colocando o dilúvio mítico e a cheia tubaronense de 74 num mesmo campo imaginal (DURAND, 2002).

A Teoria do Imaginário (DURAND, 2002) reposicionou o complexo e pouco compreendido universo da psique humana. O inconsciente, inspiração para o desenrolar do trajeto antropológico do imaginário durandiano, manifesta-se por arquétipos - 'marcas-impressão' de caráter arcaico - segundo Jung (1998). São os arquétipos que pautam imagens (PITTA, 2005) e os símbolos possibilitam o surgimento dos mitos (ELIADE, 1992) enquanto um sistema dinâmico (DURAND, 2002), uma narrativa de sentidos múltiplos (ROCHA, 2012).

O mito é um vetor social, que impulsiona e é impulsionado pelas relações e pelo meio. Pelo mito a história 'sagrada' se (re)atualiza, é transmitida e preservada (ELIADE, 1992). Nesta atmosfera imaginal, (DURAND, 2002),

Rev.Cad.Comun. Santa Maria, v.20, n.3, art 9, p.187 de 191, set/dez.2016 
não há sentido, há movimento e coerência. O dilúvio é uma narrativa mítica que preserva um lugar comum - dos gregos, aos sumérios, passando pelos mitos hebraicos, depois ameríndios até os 'Noés' europeus.

A água entra em cena enquanto elemento arquetipal: vida, purificação e fertilização para viscosidade, punição e resiliência (BACHELARD, 1998). Para além de um evento cíclico, inundações são carregadas de pregnância simbólica (DURAND, 2002), o que não difere da cheia de Tubarão. Em 1974, o município sofria sua terceira enchente; inúmeros desabrigados e duzentos mortos (VETTORETTI, 1992). De lá para cá, formou-se um mito: o mito da Grande Enchente, uma narrativa dramática, (re)contada e (re)memorada; um novo léxico para o rio que lhe confere nome (Tubarão, do tupi guarani Tuba-Nharô, pai feroz) - (VETTORETTI, 1992): belo, navegável, fonte de vida para um monstro voraz que, sob os efeitos do 'lestada' é sinônimo de enchente.

A aplicação do AT-9 revelou detalhes importantes da estrutura mítica nos microuniversos dos entrevistados, do imaginário local. Nativos e emigrantes, na primeira etapa do teste, embrenharam-se em seus traçados, com histórias e personagens distintos. Na segunda etapa, nas redações, destaque para a necessidade da interrelação entre cada representação pictórica. A terceira etapa, trouxe à tona a predileção pelo refúgio (aconchego) e pela espada, eliminando a queda (enquanto elemento arquetípico da vertigem), e do monstro (noite inquietante e morte). Na quarta etapa, no quadro síntese e em comum, a capacidade de classificar os símbolos e ordenar emoções. A quinta etapa, proposta por esta pesquisa, inseriu outras nove 'iscas' semânticas, que nos auxiliaram a conhecer, mesmo sob espaços e locais distintos na aplicação do experimento, a partilha de um mesmo momento, convergindo microuniversos míticos para uma matriz, uma comunidade imaginada, consubstanciando um campo simbólico comum e, portanto, análogo à narrativa do dilúvio mítico: a ocupação desordenada, sinônimo do pecado; das comunidades, uma pré e outra pós-74 - esta última imaginada que os faz reviver o mito da Grande enchente; a força das águas, encomenda de um Deus punitivo; Irmoto, jovem prefeito à época, considerado um 'herói' local; os testemunhos, que reverberam em cada diálogo local e nos eventos que relembram o fato, fazendo-os partilhar de uma mesma atmosfera; e uma aliança, uma cidade reconstruída pela solidariedade pós-enchente, que alimenta o paradoxal compromisso de não cicatrizar em favor da coerência comunitária imaginal que os faz pertencer.

Rev.Cad.Comun. Santa Maria, v.20, n.3, art 9, p.188 de 191, set/dez.2016 


\section{Considerações finais}

Para além da materialidade, inundações são narrativas míticas impregnadas de imaginário. O AT-9, sendo adicionado de uma quinta etapa proposta, evidenciou - a partir do mito da Grande Enchente tubaronense de 1974 e na transversalidade das narrativas - elementos que presentificam o dilúvio mítico, por meio de imagens e símbolos que também acessam uma comunidade imaginada. Percebeu-se pelos estímulos arquetípicos do protocolo e pelas iscas semânticas, campos simbólicos comuns, potencial motor e criador nos universos míticos (individuais e coletivos), perpetuação de narrativas e, sobretudo, sintonia entre o mito local e o dilúvio universal; conexões que reforçam a ideia 'do eterno retorno' (ELIADE, 1992), uma vez que cessar tais narrativas (e angústias) seria sinônimo de perda da identidade. Logo, as recorrências e convergências do imaginário tem no dilúvio mítico uma matriz imaginal de identidade local após uma enchente. A grande enchente que se mantem presente no imaginário social que tem sua expressão nas narrativas, atos e ritos do cotidiano local. E esta recorrência simbólica funciona como elo de pertencimento. 


\section{REFERÊNCIAS}

ANDERSON, Benedict. Comunidades Imaginadas: reflexões sobre a origem e a expansão do nacionalismo. Lisboa: edições 70, 2005.

BACHELARD, Gaston. A água e os sonhos: ensaio sobre a imaginação da matéria. São Paulo: Martins Fontes, 1998.

DURAND, Gilbert. As estruturas antropológicas do imaginário: introdução à arquetipologia geral. São Paulo: Martins fontes, 2002.

DURAND, Y. A Exploração do Imaginário: Introdução a modelização dos universos míticos. Trad. Loureiro, A M L. Brasília: 2002.

ELIADE, Mircea. Mito do eterno retorno. São Paulo: Mercuryo, 1992.147p

HALL, Stuart; SOVIK, Liv. Da diáspora: identidades e mediações culturais. Belo Horizonte: Ed. UFMG, 2003.

JUNG, C. G. (Carl Gustav). A vida simbólica: escritores diversos. Petrópolis: Vozes, 1998.

LEGROS, Patrick et al. Sociologia do imaginário. Porto Alegre: Sulina, 2007.

MACHADO, César do Canto. Tubarão 1974: fatos e relatos da grande enchente. Tubarão: Unisul, 2005.

MAFFESOLI, Michel. O conhecimento comum: introdução à sociologia compreensiva. São Paulo: Sulina, 2007.

PITTA, Danielle Perin Rocha. Iniciação à teoria do imaginário de Gilbert Durand. Rio de Janeiro: Atlântica Editora, 2005.

ROCHA, Everaldo P. Guimarães. O que é mito. São Paulo: Brasiliense, 2012.

SANTOS, Marcos Ferreira; ALMEIDA, Rogério de. Aproximações ao imaginário: bússola de investigação poética. São Paulo: Képos, 2012.

SILVA, Juremir Machado da. Tecnologias do imaginário. Porto Alegre: Sulina, 2003.

TURCHI, Maria Zaira. Literatura e antropologia do imaginário. Brasília: Editora da UnB, 2003.

VETTORETTI, Amadio. História de Tubarão: das origens ao século XX. Tubarão:

Prefeitura Municipal, 1992. 


\section{Resumo sobre autores:}

Heloisa Juncklaus Preis Moraes

Doutora em Comunicação Social pela PUC-RS. Docente do Programa de Pós-Graduação em Ciências da Linguagem da Universidade do Sul de Santa Catarina. Coordenadora do Núcleo de Estudos em Imaginário e Cotidiano (https://www. facebook.com/imaginarioecotidiano/).E-mail: heloisapreis@ hotmail.com

Willian Corrêa Máximo

Mestre e Doutorando em Ciências da Linguagem na Universidade do Sul de Santa Catarina. Integrante do Núcleo de Estudos em Imaginário e Cotidiano (https://www.facebook.com/ imaginarioecotidiano/).E-mail:willian.maximo@unisul.br

RECEBIDO EM: 30/06/2016

ACEITO EM: 22/07/2016 